\title{
Etnografia de Idosos que moram sozinhos: desafios e possibilidades
}

\author{
Leidelene Oliveira da Silva ${ }^{l}$; Virgínia Maria Mendes Oliveira Coronago ${ }^{2}$
}

\begin{abstract}
Resumo: O envelhecimento é um processo que todo indivíduo experimenta em algum momento de sua existência e pode ser conceituada como uma fase da vida onde o ser humano enfrenta diversas dificuldades, principalmente nas atividades rotineiras, pois a senescência traz vulnerabilidade, além da constante dependência dos outros. De acordo com a Organização Mundial da Saúde - OMS, a população acima e 60 anos aumentará nas próximas décadas, pois seus estudos apontam que no ano de 2025 haverá mais 800 milhões de pessoas com idade superior a 65 anos em todo o mundo (NUNES, et al., 2009). Assim analisamos a importância de conhecer as reais condições de vida da pessoa idosa e como estas, enfrentam os desafios comuns a esse fase da existência. O estudo delimita como objetivo geral avaliar o perfil de idosos que moram sozinhos. Será realizado com pessoas idosas participantes do Projeto Vida Ativa. Iniciaremos identificando o perfil sócio/cultural/demográfico da população estudada; analisar a qualidade de vida dos participantes do estudo e investigar os motivos que os levaram a residirem sozinhos. Trata-se de uma pesquisa qualitativa, baseada nos pressupostos etnográficos, que inclui a observação participante, entrevistas semi-estrutradas e elaboração de diário de campo. As informações serão obtidas, a princípio no Centro de Cultura Camilo de Jesus Lima, lócus de desenvolvimento do projeto e posteriormente nas residências dos idosos selecionados. Para análise das informações obtidas utilizaremos a metodologia interpretativa sugerida pelo antropólogo Clifford Geertz (1997).
\end{abstract}

Palavras-Chave: Envelhecimento. Saúde. Etnografia. Qualidade de Vida.

\section{Ethnography of the elderly people who live alone: challenges and possibilities}

\begin{abstract}
Aging is a process that every individual experiences at some point in life and can be conceptualized as a phase of life where the human being faces several difficulties, especially in routine activities, because senescence brings vulnerability, besides the constant dependence of the others. According to the World Health Organization (WHO), the population above 60 years age will increase in the coming decades, as their studies indicate that by the year 2025 there will be another 800 million people over the age of 65 worldwide (NUNES, Et al., 2009). Thus we analyze the importance of knowing the real conditions of life of the elderly people and how they face the challenges common to this phase of existence. The objective of this study is to evaluate the profile of the elderly living alone. It will be done with elderly people participating in the Vida Ativa Project. We will start by identifying the socio-cultural / demographic profile of the studied population; Analyze the quality of life of study participants and investigate the reasons that led them to reside alone. This is a qualitative research, based on ethnographic assumptions, which includes participant observation, semi-structured interviews and field diary writing. The information will be obtained, initially at the Camilo de Jesus Lima Culture Center, the project's locus of development and later in the residences of the selected elderly. For the analysis of the information obtained we will use the interpretative methodology suggested by the anthropologist Clifford Geertz (1997).
\end{abstract}

Keywords: Aging. Health. Ethnography. Quality of life.

\footnotetext{
${ }^{1}$ Graduanda do curso de Enfermagem pela Faculdade Independente do Nordeste - FAINOR, Vitória da Conquista - BA.

Autor correspondente: leidelenee@gmail.com ;

${ }^{2}$ Docente do curso de Enfermagem pela Faculdade Independente do Nordeste - FAINOR, Vitória da Conquista - BA
} 
Id on Line Revista Multidisciplinar e de Psicologia

Id on Line Multidisciplinary and Psycology Journal

\section{Introdução}

O envelhecimento é um processo que todo indivíduo experimenta em algum momento de sua existência e pode ser conceituada como uma fase da vida onde o ser humano enfrenta diversas dificuldades (FERREIRA et al, 2012). De acordo com a Organização Mundial da Saúde - OMS, a população acima e 60 anos aumentará nas próximas décadas, pois seus estudos apontam que no ano de 2025 haverá mais 800 milhões de pessoas com idade superior a 65 anos em todo o mundo (NUNES, et al., 2009).

Para Camacho (2010) esse processo universal pode ser compreendido por uma redução das atividades funcionais e possui algumas tendências em relação as enfermidades que levam continuamente a construção de políticas públicas para o idoso tanto no âmbito internacional, assim como, no âmbito brasileiro. Essas políticas estão voltadas não somente para os idosos, como também para os profissionais da saúde, visando a sua divulgação e implementação.

O envelhecimento populacional é um grande triunfo para humanidade, mas também representa um grande desafio. Em 1950, havia 205 milhões de pessoas com 60 anos ou mais no mundo. Em 2012, o número de pessoas mais velhas aumentou para quase 810 milhões. Projetase que esse número alcance 1 bilhão em menos de 10 anos e que duplique até 2050, alcançando 2 bilhões (SANTOS, 2013).

Quando o indivíduo atinge a idade de 60 anos, começa a apresentar um índice mais elevado de morbidade e estão também mais susceptíveis para desenvolver fatores agravantes que necessitem de acompanhamento médico para saná-lo, assim como, por muitas vezes necessita de um acompanhamento de um cuidador (VICTOR, et al., 2009).

Todavia, inúmeros idosos cuidam de si até uma idade bem avançada e precisam apenas de informações e ajuda para realização de pequenas tarefas mais específicas (SOUZA, 2012). O que leva muitos idosos a morarem sozinho. A decisão de morar sozinho, parte muitas vezes do próprio idoso motivado por fatores como: perdas humanas, insuficiência econômica, aposentadoria e abandono ou descaso e seus familiares (RAMOS et al., 2010).

Nessa perspectiva, levando-se em consideração que o processo do envelhecimento carrega consigo muitas alterações anátomo fisiológicas, é válido pensar em traçar estratégias para aproveitar e viver a vida de forma harmoniosa, equilibrada e com qualidade de vida (MOREIRA, et al. 2013). 
Diante das necessidades existentes para os idosos claramente expressadas, tanto na literatura, quanto no cotidiano demonstrado nas mídias de telecomunicação, viu-se a necessidade de entender de que forma os idosos que moram sozinhos de um determinado município localizado no interior da Bahia, estão sobrevivendo, mesmo com as dificuldades e limitações próprias da idade. Vale salientar ainda que este estudo busca entender o porquê destes estarem enfrentando esta fase de suas vidas sem acompanhamento de qualquer familiar ou acompanhante. É importante ressaltar ainda que a maioria dos idosos possuem diversas limitações, no qual são desencadeadas pela própria idade.

Por isso, esta pesquisa será relevante também para toda a sociedade que deseja compreender sobre as necessidades específicas do idoso e a forma como estes da cidade local vivem. Servirá também para os profissionais da saúde, acadêmicos e pesquisadores que tenham o interesse de se atualizar diante o real cenário no qual tem se encontrado os idosos, principalmente no que diz respeito aos idosos que moram sozinhos.

Diante dos estudos realizados, surge a pergunta norteadora dessa pesquisa: como o idoso encara a opção de viver sozinho?

Visto o exposto este estudo teve como objetivo descrever como vivem os idosos que moram sozinhos, buscando identificar os desafios e as possibilidades encontradas por eles.

\section{Metodologia}

Trata-se de um estudo exploratório e descritivo, com abordagem qualitativa, realizado em um Centro de convivência para Idosos do Município de Vitória da Conquista/Bahia. Os participantes do estudo foram representados por seis idosos com idade igual ou superior a 60 anos de ambos os sexos, que frequentam um grupo de convivência para idosos, que moram sozinhos e que aceitaram participar da pesquisa.

Foram utilizados dois instrumentos para coleta dos dados: um questionário sóciodemográfico e uma entrevista semi-estruturada. Essa entrevista foi realizada pela própria pesquisadora de maneira informal, seguindo um roteiro de perguntas, onde os entrevistados ficaram livres para se expressar da forma mais clara possível. Muitos acabavam expandindo as 
Id on Line Revista Multidisciplinar e de Psicologia

Id on Line Multidisciplinary and Psycology Journal

questões abordadas para questões mais pessoais de sua vida, demonstrando assim uma certa segurança para com a pesquisadora que estava executando a entrevista.

Com o intuito de construir uma caracterização dos participantes do estudo foi estabelecido um questionário sócio-demográfico com questões a cerca da idade, sexo, condições de moradia, hábitos de vida saudável, naturalidade, estado civil e se possui filhos.

Para descrever os desafios e as possibilidades de idosos que moram sozinhos foi realizada uma entrevista, com roteiro baseado em questões norteadoras, como: Por que mora sozinho(a)?; a quanto tempo mora sozinho (a)?; quais as dificuldades de se morar sozinho (a)? já sofreu algum tipo de preconceito? Já sofreu algum tipo de violência?

Primeiramente foi realizada uma visita informal ao grupo de convivência para apresentação do pesquisador e do estudo. Posteriormente, foi marcado um novo encontro, em dia e horário definidos pelos idosos para aplicação do questionário e para a realização da entrevista. Esse processo ocorreu durante o período de outubro de 2016.

As entrevistas foram realizadas de forma individual, contando com a presença apenas do idoso e do pesquisador. Estas foram gravadas com a autorização do idoso, sendo posteriormente ouvidas e transcritas para análise das informações. Ressalta-se que tanto a aplicação do questionário, quanto a entrevista foi realizada na residência dos idosos, para preservar a autonomia das respostas.

Todas as entrevistas foram gravadas com o celular da pesquisadora de forma separada, onde cada entrevistado, passou pelo seu processo de entrevista separadamente, respeitando assim a privacidade das informações da cada um dos entrevistados.

Posteriormente a coleta das informações foi realizada análise, fundamentada teoricamente nos pressupostos teóricos, obedecendo os padrões exigidos para este estudo. As falas dos entrevistados foram transcritas tornando possível um melhor entendimento das questões abordadas e respostas ofertadas pelos idoso. Para cada resposta, foi realizada a comparação com outras abordagens teóricas, sendo realizado a partir daí um comparativo deste estudo com outros estudos já publicados.

Para análise das informações obtidas utilizaremos a metodologia interpretativa sugerida pelo antropólogo Clifford Geertz (1997).

Primeiramente, o projeto foi enviado ao Comitê de Ética e Pesquisa da Faculdade Independente do Nordeste e após sua aprovação os questionários foram aplicados pela 
Id on Line Revista Multidisciplinar e de Psicoloqia

Id on Line Multidisciplinary and Psycology Journal

pesquisadora com os idosos participantes da pesquisa que por meio da assinatura do termo de consentimento, se dispuserem a responder as perguntas.

Na medida em que as informações foram coletadas iniciamos uma pré-análise, com o objetivo de identificar os aspectos comuns e incomuns, o que gera a reflexão sobre questões relativas ao fenômeno; assim, faz-se necessário, muitas vezes, o retorno ao campo da pesquisa para tentar respondê-las, o que caracteriza a descrição densa das experiências apreendidas. Todas as entrevistas foram submetidas à análise interpretativa, Geertz (1997) compreendida por quatro etapas, a saber:

a) Organização das informações: Processo de familiarização e organização das informações. A organização ou ordenação das informações, segundo Minayo (2004) envolve a transcrição dos dados das entrevistas, das observações e das notas de campo, e a montagem de um mapa horizontal das descobertas do pesquisador ou um texto. Para Geertz (1989), a hermenêutica dialética considera o texto como a cultura dos informantes. Nesse caso em estudo, os significados da experiência do idoso que vive sozinho que precisava ser interpretado para derivar o conhecimento científico.

b) Codificação das informações: Este foi o momento de leitura exaustiva dos textos produzidos. Após a leitura horizontal de cada um, delineou-se as seções do texto e feito comentários à margem esquerda da transcrição buscou-se identificar a coerência das informações, ou seja, aquilo que era comum/incomum nos discursos dos informantes. Esses comentários incluíram impressões pessoais e aspectos de interesse e planos de trabalho. Foram identificadas palavras, frases, assuntos ou conceitos. Minayo (2007) denomina esse momento de "leitura flutuante", na qual busca-se apreender as estruturas de relevância para os atores sociais, o que as suas ideias transmitem e os momentos e posturas frente ao tema investigado.Assim, a codificação das informações teve como base o tema de pesquisa, os objetivos e os pressupostos teóricos. As seções grifadas no texto foram recortadas e agrupadas sob formas de arquivos separados, de modo que todos os dados fossem incluídos de maneira significativa.

c) Identificação das unidades de significação e dos núcleos de significados e concluiremos as etapas de ordenação e classificação dos dados, com a interpretação da lógica interna dos discursos dos envolvidos. 
Id on Line Revista Multidisciplinar e de Psicologia

Id on Line Multidisciplinary and Psycology Journal

d) Os núcleos de significados: Concluídas as etapas de ordenação e classificação dos dados deu-se início a interpretação da lógica interna do grupo sobre a experiência de viver sozinho. Nessa etapa, realizou-se uma releitura das unidades de significado considerando a seguintes questões:

- Os objetivos da pesquisa;

- Os pressupostos teóricos adotados;

- Os contextos dos participantes.

A interpretação dos resultados partiu das narrativas dos informantes, do referencial da antropologia interpretativa e de reflexões pessoais. A interpretação é um ato em que o pesquisador busca compreender e explicar o sentido da ação individual ou coletiva frente a uma experiência. Nesse sentido, o significado da experiência de idosos que moram sozinhos frente os desafios e dificuldades congrega ações humanas apreendidas culturalmente, que dependem dos aspectos estabelecidos pelo senso comum (ALVES, 1993).

O projeto foi submetido ao Comitê de Ética em Pesquisa da Faculdade Independente do Nordeste com parecer de aprovação $n^{\circ} 1.756 .028$. Após a provação do projeto foi dada início a coleta dos dados. Para isso, todos os participantes foram informados a respeito dos objetivos do estudo mediante o diálogo informal no local da pesquisa e assinaram um Termo de Consentimento Livre e Esclarecido de acordo com a Resolução do Conselho Nacional de Saúde (CNS) $n^{\circ}$. 466/12 para pesquisa com seres humanos. Vale lembrar que o anonimato dos participantes do estudo foi preservado, utilizando-se apenas nomes de flores para caracterizar os, sendo elas: Bromélia, Violeta, Orquídea, Margarida, Copo de leite e Antúrio.

\section{Resultados e Discussões}

Por meio da observação participante e da entrevista semi-estruturada foi possível determinar os resultados. Com a análise das respostas obtidos pelos entrevistados, foi possível efetuar a classificação conforme os objetivos classificados para esta pesquisa.

De acordo com a entrevista de Margarida foi possível identificar que: durante a entrevista a paciente relatou ter descoberto o câncer com 60 anos, "já tem 15 anos". Relata fazer 
Id on Line Revista Multidisciplinar e de Psicologia

Id on Line Multidisciplinary and Psycology Journal

consultar frequentes com o oncologista, ter feito reposição hormonal e ter realizado a constituição da mama.

Segundo Frazão (2013) O câncer de mama tem sido a neoplasia maligna que mais tem atingido as mulheres em todo o território mundial e que tem causado mais mortes no país.

A entrevistada ainda relatou não possui familiares na cidade de Vitória da Conquista. Possui nível superior em serviço social e teologia. Relata participar de grupos de terceira idade no SESC. Não realiza nenhum tipo de atividade física devido um problema com a catarata. Por isso, de acordo Fitness (2013) com o hábito de se realizar e praticar atividade física o idoso torna-se capaz de controlar e evitar algumas doenças, reduzindo, portanto, a probabilidade de desenvolver disfunções cardiovasculares, diabetes, osteoporose, depressão e ansiedade.

Para a entrevistada ainda, a participação do idoso na sociedade encontra-se de forma moderada, mas precisa melhorar, conforme fala: "está melhor que antigamente".

Santos (2013) em sua pesquisa afirmou que os direitos e as garantias dadas aos idosos nas últimas décadas tem assegurado o crescimento desta faixa etária da população. Tal informação permitiu afirmar que o envelhecimento tem se tornado possível também graças as discussões políticas e sociais, direcionadas para a prevenção e promoção da saúde do idoso.

$\mathrm{Na}$ entrevista Margarida relatou ainda que na sua concepção não existe preconceito contra o idoso não existe conforme a fala: "Pelo menos no meu conceito não". Relata ainda não ter sofrido nenhum tipo de lesão corporal e mental e muito menos agressão física. Conforme os dados emitidos por D'Avila (2011) os danos contra os idosos mais registrados nos últimos anos tem sido os de maus tratos, abandono e apropriação de bem de idoso, ameaça, injúria, lesão corporal, estelionato; e as perturbações da tranquilidade e do sossego, sendo a maioria das vítimas são mulheres.

Relata ter resido toda sua juventude no estado de São Paulo, dentro do Tribunal de Justiça como assistente social. Aposentou-se cedo, tendo apenas 50 anos de idade. Relata ainda que quando chegou em Vitória da Conquista encontrou dificuldade para entrar novamente no mercado de trabalho devido a idade. Afirma ainda que nunca passou necessidade, que era concursada e que sempre teve saúde. Nunca mais apresentou nenhuma alteração patológica, somente o Parkinson que começou a se manifestar à alguns anos. Considera-se uma pessoa feliz e relata ser feliz. 
Id on Line Revista Multidisciplinar e de Psicologia

Id on Line Multidisciplinary and Psycology Journal

Conforme entrevista realizada com Orquídea, a mesma afirmou ser participante do projeto vida ativa e gostar muito da atividade desenvolvida pelo projeto. Nascida em 28 de outubro de 1942, relata ser viúva, brasileira, nascida na cidade de Ubaitaba e reside há 32 anos na antiga Urbis em Vitória da Conquista. Mora sozinha em sua residência. Relata ter 04 filhos sendo 3 mulheres e 01 homem. Considera-se uma pessoa saudável mesmo sendo portadora da Hipertensão Arterial e afirma ainda que "Sente muita dor nos ossos". De acordo o manual do UNASUS (2010) A hipertensão arterial sistêmica (HAS) nada mais é que uma condição clínica desencadeada por vários fatores e por níveis elevados e sustentados de pressão arterial (PA).

Possui o ensino fundamental completo. Sobre a participação do idoso hoje na sociedade relatou ser bem mais ativa, mas ainda precisa mudar, sendo considerada moderada -"aainda precisa melhorar". Relata também que o preconceito contra o idoso é bem pouco. Já foi assalta duas vezes, mas as outras mazelas não. $\mathrm{O}$ entrevistado relata ter participado de diversas atividades que envolviam os idosos. Relata ter sofrido muito com o falecimento do esposo "16 anos que o esposo faleceu". Frequenta muito a igreja e diz ser uma distração.

Conforme os dados disponíveis no artigo de Holanda et al. (2013) a Política Nacional do Idoso e Estatuto do Idoso tornou possível uma melhor participação social do idoso, quebrando, portanto, com o paradigma de que a pessoa velha pode ser caracterizada apenas por uma imagem de fragilidade, inutilidade e solidão.

Copo de Leite, entrevistada de 83 anos, sexo feminino, viúva, residente no centro, município de Vitória da Conquista, mora sozinha e relata fazer uso do medicamento Rivotril a mais de 10 anos. Durante a entrevista informou que teve 10 filhos e destes somente 07 encontram-se vivos. Se considera uma pessoa saudável mesmo apresentando problemas na tireoide e o glaucoma.

É muito comum a expressão "eu tenho tireoide", como se isso fosse um problema de saúde. A tireoide é só mais um órgão do corpo humano como os rins, o coração, o pâncreas. Contudo, os problemas mais comuns apresentados pelo órgão é o hipertireoidismo e o hipotireoidismo conforme afirma Pinheiro (2016).

A entrevistada afirma ter o ensino fundamental completo e participar de todas as atividades físicas oferecidas pelo grupo de terceira idade. Quando abordada sobre o preconceito conta o idoso, a mesma informou que isso não existe mais e que nunca sofreu nenhum tipo de preconceito. Refere também nunca ter sofrido nenhum tipo de violência ou abuso. Afirma ter 
Id on Line Revista Multidisciplinar e de Psicologia

Id on Line Multidisciplinary and Psycology Journal

conhecido sobre o estatuto do idoso no grupo de $3^{\circ}$ idade no qual vem participando. Considerase uma pessoa feliz, mesmo estando morando sozinha.

A participante Antúrio possui 60 anos, solteira, brasileira, nascida em Vitória da Conquista e residente no bairro recreio. Mora sozinha e não possui filhos. Considera-se uma pessoa saudável "Eu me cuido muito". Não possui nenhuma patologia, somente alteração no colesterol e triglicerídeos.

O Colesterol é um composto químico gorduroso que integra a membrana das células do organismo. Já o triglicerídeo pode ser conceituado como sendo a principal gordura originária da alimentação que pode ser sintetizada pelo organismo. Os altos níveis desses dois, podem acarretar no desenvolvimento das doenças coronarianas e cardiovasculares conforme afirma a SOCERJ - Sociedade de Cardiologia do Rio de Janeiro (2013).

Antúrio possui o ensino médio completo e fez o curso de técnico segurança do trabalho. Participa de todas as atividades disponível para os idosos, desde as culturais até as de atividade física. De acordo a entrevistada, a participação do idoso na sociedade pode ser considerada moderada e ainda precisa melhorar. Os grupos de idosos são pequenos. Acredita que ainda possui muito preconceito contra o idoso na sociedade "Já me passaram o troco errado no supermercado e insistiu que eu estava errada". Já foi vítima de assalto e estupro quando era jovem. Relata ser "Invisível” para a família. Diz que quando sofreu a fratura no braço ficou sozinha. Que nem os irmãos ajudou ela nesse momento difícil.

De acordo o advogado Rucker (2014) estatísticas tem demonstrado que a situação dos idosos no Brasil pode ser considerada muito vulnerável, uma vez que aumenta o número de denúncias de casos de violência e abusos contra os mesmos.

Conforme a entrevista realizada com Bromélia foi possível coletar as seguintes informações: sexo feminino, 72 anos, solteira, brasileira, originária, residente e nascida em Vitória da Conquista em um bairro localizado na periferia da cidade. Relata que morar sozinha e ter dois filhos "um casal". A mesma durante a entrevista afirmou se considerar uma pessoa saudável mesmo sendo portador da Hipertensão Arterial Sistêmica e refere tomar os remédios de forma correta. Possui apenas o ensino fundamental incompleto e relata participar de atividades físicas e artísticas disponíveis nos grupos de terceira de idade.

De acordo os dados emitidos por Antonelli (2015), escritor do Jornal Gazeta do Povo o Brasil está longe de ser um paraíso para os idosos, devido a falta de segurança pública, a má qualidade 
Id on Line Revista Multidisciplinar e de Psicologia

Id on Line Multidisciplinary and Psycology Journal

do transporte urbano e a baixa escolaridade, fatos estes que tem sido considerado grandes desafios a serem enfrentados pelo país.

Relata ainda que não faz caminhada devido "já caminhar muito fazendo outras atividades". Na opinião da entrevistada é moderada e ainda precisa melhorar. Ela acredita que existe o preconceito contra os idosos ainda na sociedade de forma moderada. Já foi estuprada quando nova e furtada "cortaram minha bolsa na praça da bandeira". Relata saber e ter o estatuto do idoso em sua residência.

Segundo a entrevista realizada com Violeta, foi possível coletar as seguintes informações: sexo masculino, 69 anos, viúvo há 04 anos e oito meses, brasileiro, originário de São Miguel das Matas, residente no município de Vitória da Conquista no bairro Alto Marom, durante a entrevista relata que é deficiente visual desde os 17 anos e morar sozinho mas mesmo sendo deficiente faz todas as atividades em sua residência "Dô brilho nas panelas e tiro o pó"; Afirma ter somente 01 filha que mora na cidade de Salvador. Relata que os familiares não moram na cidade e que ainda tem mãe viva " ela tem 91 anos". Se considera uma pessoa saudável mesmo com a deficiência existente. Relata ainda que realizou apenas o ensino médio não completo e participar de atividades artísticas e físicas. Estuda na avenida Ciqueira Campos, o curso de Brailer. Quando abordado sobre a participação do idoso na sociedade, o mesmo fala que isso ocorre de forma moderada, não identificando mesmo assim nenhum tipo de preconceito. Afirma fazer caminhada e participar das atividades do grupo.

Quanto as dificuldades para os idosos, acredita que ainda precisa melhorar muito mas que é bem recebido dentro dos transportes. Relata ainda que não possui preconceito contra o idoso e que o mesmo é que tem que se valorizar. Afirma ainda ter sido acometido sim, foi assaltado 08 vezes em São Paulo e ser católico. Quando abordado sobre a existência do estatuto do idoso, e que percebe que os fatos contidos nele não são respeitados como deveria. O mesmo relata ainda conhecer a sua existência e afirma tê-lo em sua residência. Alimenta-se de forma saudável e equilibrada, que tem alguém em casa para lhe ajudar e que quando não esta em casa, que se alimenta no bandejão do restaurante popular. Afirma que os vizinhos os ajuda muito "Faz um prato de comida e leva para mim". Não recebe visita de seus familiares e que se vira sozinho, sem se lamentar da vida "não podemos lamentar da vida para não ficar doente". 
Tabela 01: Desafios e Possibilidades

\begin{tabular}{|c|c|c|}
\hline PARTICIPANTES & $\begin{array}{c}\text { DESAFIOS } \\
\text { EXCLUSÃO SOCIAL/ } \\
\text { ISOLAMENTO E INDICATIVO } \\
\text { DE DEPESSÃO }\end{array}$ & $\begin{array}{c}\text { POSSIBILIDADES } \\
\text { REDES DE SOLIDARIEDADE/ } \\
\text { GRUPOS DE CONVIVÊNCIA/ } \\
\text { RESILIÊNCIA/ OPÇÃO DE } \\
\text { MORAR SOZINHO }\end{array}$ \\
\hline MARGARIDA & $\begin{array}{l}\text { Não realiza nenhum tipo de atividade } \\
\text { física devido um problema com a } \\
\text { catarata. }\end{array}$ & $\begin{array}{l}\text { A participação do idoso na } \\
\text { sociedade encontra-se de forma } \\
\text { moderada, mas precisa melhorar, } \\
\text { conforme fala: "está melhor que } \\
\text { antigamente". }\end{array}$ \\
\hline ORQUÍDEA & $\begin{array}{l}\text { Considera-se uma pessoa saudável } \\
\text { mesmo sendo portadora da } \\
\text { Hipertensão Arterial e afirma ainda } \\
\text { que "Sente muita dor nos ossos". }\end{array}$ & Faz aula de pianos \\
\hline COPO DE LEITE & $\begin{array}{l}\text { Mora sozinha e relata fazer uso do } \\
\text { medicamento Rivotril a mais de } 10 \\
\text { anos. } \\
\text { Apresenta problemas na tireoide e o } \\
\text { glaucoma. }\end{array}$ & $\begin{array}{l}\text { Participar de todas as atividades } \\
\text { físicas oferecidas pelo grupo de } \\
\text { terceira idade. }\end{array}$ \\
\hline ANTÚRIO & $\begin{array}{l}\text { Acredita que ainda possui muito } \\
\text { preconceito contra o idoso na } \\
\text { sociedade "Já me passaram o troco } \\
\text { errado no supermercado e insistiu que } \\
\text { eu estava errada". Já foi vítima de } \\
\text { assalto e estupro quando era jovem. } \\
\text { Relata ser "Invisível" para a família. } \\
\text { Diz que quando sofreu a fratura no } \\
\text { braço ficou sozinha. Que nem os } \\
\text { irmãos ajudou ela nesse momento } \\
\text { difícil. }\end{array}$ & $\begin{array}{l}\text { Participa de grupos de } \\
\text { convivência }\end{array}$ \\
\hline VIOLETA & $\begin{array}{l}\text { "Faz um prato de comida e leva para } \\
\text { mim" } \\
\text { "Dô brilho nas panelas e tiro o pó" }\end{array}$ & Opção de morar sozinho \\
\hline BROMÉLIA & $\begin{array}{l}\text { portador da Hipertensão Arterial } \\
\text { Sistêmica. Possui apenas o ensino } \\
\text { fundamental incompleto }\end{array}$ & $\begin{array}{l}\text { participa de atividades físicas e } \\
\text { artísticas disponíveis nos grupos de } \\
\text { terceira de idade. }\end{array}$ \\
\hline
\end{tabular}

Fonte: entrevista realizada com os 06 idosos em outubro de 2016, Vitória da Conquista - Bahia.

De acordo com as falas evidenciadas durante a entrevista com os idosos, foi possível perceber que, muitas são as dificuldades enfrentadas por eles durante o seu cotidiano, contudo, nenhuma delas tem sido pelo fato de estarem morando sozinhos. Duas das entrevistadas não se casaram, acredita-se que tenha sido pelos abusos sofridos pelas mesmas quando eram mais novas, conforme relato durante a entrevista.

Foi possível perceber também que as publicações bibliográficas relatam sobre a falta de participação do idoso na sociedade assim como sobre as dificuldades enfrentadas pelos mesmo 
Id on Line Revista Multidisciplinar e de Psicologia

Id on Line Multidisciplinary and Psycology Journal

em relação aos casos de violência e abusos sofridos. Contudo, foi possível observar que os idosos entrevistados relataram não sofrer nenhum tipo de preconceito em relação a idade.

Algo que chamou atenção foi o fato da auto-estima de todos os entrevistados. Todos demonstram ser muito alegres e receptivos, mesmo apresentando problemas de saúde. Alguns relataram que não podiam desistir nem lamentar da vida, pois se consideravam felizes acima de tudo. Diante dessa perspectiva é possível afirmar que mesmo com as dificuldades existentes para os idosos na fase na senescência, os entrevistados tem enfrentado com muita tranquilidade essa sua condição, sem apresentar mazelas mais graves que comprometam a sua sobrevivência.

\section{Considerações Finais}

São muitas as dificuldades no qual tem sido expostos os idosos em nossa sociedade e visto essa premissa, este estudo buscou entender de que forma isso vem acontecendo e como tem afetado a população na senescência. Com os dados coletados neste estudo, foi possível perceber que muitas das inseguranças e situações em que o idoso se encontrava, tem sido sanada, ou seja, tem se transformado em outra realidade. Os idosos que moram sozinhos, antes eram tidos como fragilizados e impossibilitados de darem continuidade em suas vidas. Hoje, conforme a demonstração emitida pela pesquisa, é possível afirmar que o idoso não pode ser mais considerado uma classe fragilizada da sociedade, pois, estes, tem enfrentado problemas que muitos jovens não são capazes de enfrentar.

Contudo, é possível afirma ainda que, mesmo com as superações demonstradas pelos idosos neste estudo, não pode ser deixado de lado o fato deles estarem inseridos no grupo de risco, ou seja, estão mais susceptíveis ao desenvolvimento das doenças que podem acometer a pessoa idosa, e isso provoca involuntariamente uma dependência não prevista pelos mesmo.

Diante dessa afirmativa, sugere-se que mais pesquisas sejam realizadas nessa linha de raciocínio, pois promoverá dados capazes de solucionar os problemas enfrentados ainda por alguns idosos. Servirá também como ferramenta para novos estudos científicos. Partindo desse pressuposto, é possível afirmar que os objetivos propostos foram alcançados. 
Id on Line Revista Multidisciplinar e de Psicologia

Id on Line Multidisciplinary and Psycology Journal

\section{Referências}

BRASIL, MINISTÉRIO DA SAÚDE. Secretaria de Atenção a Saúde. Guia prático do cuidador, 2008. Disponível em: http://bvsms.saude.gov.br/bvs/publicacoes/guia pratico cuidador.pdf acessado em 28 de abril de 2016 as 13:53.

. Atenção à Saúde da Pessoa Idosa e Envelhecimento. Brasília - DF, 2010 A. Disponível em:

http://bvsms.saude.gov.br/bvs/publicacoes/atencao_saude_pessoa_idosa_envelhecimento_v12.pdf acessado em 28 de abril de 2016 as 16:49.

Sistema de Indicadores de Saúde e Acompanhamento de Políticos do Idoso - SISAP. 2010. Disponível em: http://www.saudeidoso.icict.fiocruz.br/index.php?pag=polit acessado em 29 de abril de 2016 as 12:30.

CAMACHO, A. C. L. F. Políticas públicas para a saúde do idoso: revisão sistemática políticas públicas para a saúde. Revista Brasileira de Enfermagem, Brasília 2010. Mar-abril; 63 (2): 27984. Disponível em: http://www.scielo.br/pdf/reben/v63n2/17.pdf acessado em 28 de abril de 2016 as 12:52.

CAMARANO, A. A. Envelhecimento da População $\begin{gathered}\text { Brasileira: Uma Contribuição } \\ \text { Demográfica, }\end{gathered}$
2002. http://repositorio.ipea.gov.br/bitstream/11058/2091/1/TD_858.pdf acessado em 27 de abril de 2016 as 11:41.

CAMARGOS, M. C. S. Idosos que vivem sozinhos: como eles enfrentam dificuldades de saúde. 2008.

Disponível

em:

http://www.abep.nepo.unicamp.br/encontro2008/docsPDF/ABEP2008_1605.pdf acessado em 21 de abril de 2016 as 19:59.

D'AVILA, M. As diversas formas de violência contra o idoso. Congresso em Foco, 2011. Disponível em: < http://m.congressoemfoco.uol.com.br/noticias/as-diversas-formas-de-violenciacontra-o-idoso/> acessado em 07 de novembro de 2016.

GARCIA, M. A. A. et al. O envelhecimento e a saúde. Revista Ciências Médicas de Campinas, 11(3): 221-231, set/dez, 2002.

GEERTZ, C. Uma descrição densa: por uma teoria interpretativa da cultura. Rio de Janeiro: Editora Guanabara Koogan, 1989. Disponível em: 〈http://moodle.fct.unl.pt/pluginfile.php/122511/mod_resource/content/0/Leituras/Geertz01.pdf > acessado em 24 de abril de 2016 as 20:45.

FITNESS, SCHERER. A importância a atividade física para os idosos. Saúde, 2013. Disponível em: < http://www.academiafernandoscherer.com.br/noticias/saude/183-a-importancia-daatividade-fisica-para-idosos > acessado em 08 de novembro de 2016 as 15:00. 
Id on Line Revista Multidisciplinar e de Psicologia

Id on Line Multidisciplinary and Psycology Journal

FRAZÃO, A. Mulheres com Câncer de Mama: as Expressões da Questão Social durante o Tratamento de Quimioterapia Neoadjuvante. Revista Brasileira de Cancerologia 2013; 59(3): 427-435. Disponível em: < http://www1.inca.gov.br/rbc/n_59/v03/pdf/13-artigo-mulheres-cancermama-expressoes-questao-social-durante-tratamento-quimioterapia-neoadjuvante.pdf $>$ acessado em 08 de novembro de 2016 as 12:30.

FERREIRA, Olívia Galvão Lucena et al. Envelhecimento ativo e sua relação com a independência funcional. Texto contexto - enferm., Florianópolis , v. 21, n. 3, p. 513-518, Sept. 2012 - Available from <http://www.scielo.br/scielo.php?script=sci_arttext\&pid=S0104$07072012000300004 \& \operatorname{lng}=\mathrm{en} \& \mathrm{nrm}=\mathrm{iso}>$. access on 05 Nov. 2016. http://dx.doi.org/10.1590/S0104-07072012000300004.

GEERTZ, C. O saber local: novos ensaios em antropologia interpretativa. Tradução de Vera Mello Joscelyne. Petrópolis, Vozes, 1997, 366 pp. Revista de Antropologia, vol. 41 no 02. São Paulo, 1998. Disponível em: <http://www.scielo.br/scielo.php?script=sci_arttext\&pid=S0034-

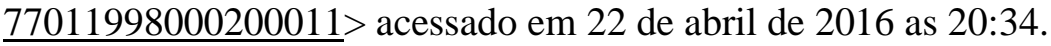

GIL, A. C. Como elaborar projeto de pesquisa. 6. Ed. São Paulo: Atlas, 2010.

HOLANDA, E. R. A Situação da Pessoa Idosa e a Atuação do Serviço Social junto a Garantia de Direitos no Instituto Amantino Câmara. 2013. Disponível em: < http://socialuern.blogspot.com.br/2013/12/a-situacao-da-pessoa-idosa-e-atuacao-do.html> acessado em 09 de novembro de 2016.

LIMA, M. C. Pesquisa-ação nas organizações: do horizonte político à dimensão formal. Gestão.Org, v. 3, n. 2, mai./ago., 2005 MACIEL, M. I. E. Disponível em: $\langle$ http://www.abepro.org.br/biblioteca/enegep2006_tr540368_8017.pdf $>$ acessado em 26 de abril de 2016 as 21:28.

LUCIA, A. C. A. Breves reflexões sobre o morar na velhice. REVISTA PORTAL de Divulgação, n.20, Abr. 2012. Disponível em: file:///C:/Users/User/Downloads/241-738-1-PB.pdf.

MATTAR, F. N. Pesquisa de marketing: edição compacta. São Paulo: Atlas, 1996.

MATTAR, F. N. Pesquisa de marketing, 3 ed. São Paulo: Atlas, 2001.

MINAYO, M. C. S. O desafio do conhecimento. São Paulo/Rio de Janeiro: Hucitec/Abrasco, 1992.

MINAYO, M. C. S. - O Desafio do Conhecimento - Pesquisa Qualitativa em Saúde - São Paulo: Hucitec, $8^{\text {a }}$ edição, 269 p 2004

MINAYO, M. C. S. O desafio do conhecimento: pesquisa qualitativa em saúde. SãoPaulo: Hucitec, 2007.

MOREIRA, R. M. et. al. Qualidade de vida, saúde e política pública de idosos no Brasil: uma reflexão teórica, 2013. 
Id on Line Revista Multidisciplinar e de Psicologia

Id on Line Multidisciplinary and Psycology Journal

NUNES, M. C. R. et al. Influência. das características sociodemograficas e epidemiológicas na capacidade funcional de idosos residentes em Ubá, Minas Gerais. Revista Brasileira de Fisioterapia, 2009. Disponível em: http://www.scielo.br/pdf/rbfis/2009nahead/aop053_09.pdf acessado em 20 de abril de 2016 as 19:54.

PINHEIRO, P. Doenças e sintomas da tireoide. MS saúde, 2016. Disponível em: < http://www.mdsaude.com/2009/02/doencas-sintomas-tireoide.html > acessado em 08 de novembro de 2016.

RAMOS, J. L. C. et al. Idosos que moram sozinhos: desafios e potencialidades do cotidiano. Revista Baiana de Enfermagem, Salvador, v. 24, n. 1, 2, 3, p. 43-54, jan./dez. 2010.

RUCKER, B. "Idoso: ser humano invisível - os direitos do idoso na sociedade"

Esse foi o tema do encontro realizado pela OAB Paraná. A advogada do Portal, Jéssica Mara Brum, participou dos debates em defesa da criação da Delegacia do Idoso em Curitiba. Cidadania e Defesa dos Direitos da Terceira Idade, 2014. Disponível em: < http://www.portalterceiraidade.org.br/wordpress/idoso-ser-humano-invisivel-os-direitos-do-idosona-sociedade/> acessado em 08 de novembro de 2016.

SANTOS, N. F. As Políticas Públicas voltadas ao idoso: melhoria da qualidade de vida ou reprivatização da velhice. Revista FSA, Teresina, v. 10, n. 2, art. 20, pp. 358-371, Abr./Jun. 2013. Disponível em: < http://www4.fsanet.com.br/revista/index.php/fsa/article/viewFile/130/97> acessado em 08 de novembro de 2016 as 13:12.

SOCERJ - Sociedade de Cardiologia do Estado do Rio de Janeiro. Colesterol e Triglicerídeos, 2013. Disponível em: < http://socerj.org.br/colesterol-e-triglicerideos/> acessado em $08 \mathrm{de}$ novembro de 2016.

UNASUS. Fundamentação teórica: Hipertensão Arterial Sistêmica - HAS. Especialização em saúde da $\quad$ Família, 2010. Disponível em: http://www.unasus.unifesp.br/biblioteca_virtual/esf/1/casos_complexos/Sergio/Complexo_11_Ser gio Hipertensao.pdf> acessado em 09 de novembro de 2016.

VITOR, J. F. et al. Perfil sociodemografico e clínico de idosos atendidos em Unidade Básica de Saúde da Família, 2009. ACTA. Paul. Enferm. 2009; 22(1): 49 - 54. Disponível em: http://www.scielo.br/pdf/ape/v22n1/a08v22n1.pdf acessado em 27 de abril de 2016 as 11:32.

Como citar este artigo (Formato ABNT):

SILVA, L.O.; CORONAGO, V.M.M.O. Etnografia de Idosos que moram sozinhos: desafios e possibilidades. Id on Line Revista Multidisciplinar e de Psicologia, Out-Nov. de 2016, vol.10, n.32, p. 3-17. ISSN: 1981-1179.

Recebido: $11 / 11 / 2016$

Aceito: 14/11/2016 